\title{
On the Potency of Online User Representation: Insights from the Sharing Economy
}

\author{
Timm Teubner, Marc T. P. Adam, and Florian Hawlitschek
}

\begin{abstract}
Online user representation (UR) is a cornerstone of platform-mediated interactions within the sharing economy. While the general usefulness of UR artifacts for facilitating online and offline interactions is widely acknowledged and understood, the underlying mechanisms and operating principles often require a more detailed analysis. In this chapter, we thus introduce a systematic framework grounded in signaling and social presence theory for analyzing UR artifacts for online platforms in general-and the sharing economy in particular. We apply our framework as a structural lens in a case study on user profiles on Airbnb, unveiling structural similarities and differences between the opposing market sides. We discuss our findings against the backdrop of emerging information systems research directions and suggest paths for future work on the sharing economy.
\end{abstract}

\section{Introduction}

An ever-increasing number of businesses in today's e-commerce landscape facilitate the renting, sharing, lending, and selling of resources. In this platform or sharing economy, platforms from $\mathrm{A}$ (irbnb) to $\mathrm{Z}$ (imride) connect providers (e.g., hosts, sellers) and consumers (e.g., guests, buyers) to co-create value. Importantly, even though many of these multisided markets facilitate interactions that take place in the physical world (e.g., accommodation or ride sharing), the initiation, trust-building, and booking processes are entirely mediated by platforms. To do so, platform companies make use of a variety of user representation (UR) artifacts to establish trust between users (Hesse et al. 2020a). In fact, platforms vary greatly with regard

T. Teubner $(\bowtie) \cdot$ F. Hawlitschek

Einstein Center Digital Future, Technische Universität Berlin, Berlin, Germany

e-mail: teubner@tu-berlin.de; florian.hawlitschek@fes-frankfurt.de

M. T. P. Adam

College of Engineering, Science and Environment, The University of Newcastle, Callaghan,

Australia

e-mail:marc.adam@newcastle.edu.au

(C) The Author(s) 2021

H. Gimpel et al. (eds.), Market Engineering, https://doi.org/10.1007/978-3-030-66661-3_10 
to how and what kind of value is created (e.g., social and/or economic; Dann et al. 2020). Since this also affects the respective need for trust and how users engage, it is not surprising that platforms also differ with regard to the array of the UR artifacts they employ. Consequently, research on the role, use, and effects of UR artifacts is also diverse in terms of domains, platforms, dependent variables, theory, methods, and publication outlets (Dann et al. 2019).

Notwithstanding the multifaceted platform landscape, we observe a range of commonalities and "best practices" in how platforms employ UR artifacts and how this, in turn, affects user perceptions and behavior. For instance, a great majority of platforms uses rating systems to keep track of their users' behavior and reputation. Star ratings and text reviews are commonly considered the "hardest" currency when it comes to substantiating one's credibility for online transactions (Teubner et al. 2017). These cues (1) are provided by others, (2) aggregate the experience of prior transaction partners, and (3) can only be issued by these partners (e.g., guests or passengers). In particular this seclusion makes such cues reliable (very much in contrast to "open" product review platforms, on which anyone can rate anythingbe it products, hotels, restaurants, or medical doctors). While rating systems do not come without shortcomings and side effects (e.g., fake reviews, rating inflation; Filippas et al. 2017; Teubner and Glaser 2018), they have become a central pillar of many platforms' operations and - from the individual user perspective—an essential tool to present oneself, evaluate others, and successfully engage in online markets (Teubner et al. 2017). In view of the importance and prominence of rating systems, other-"softer"-UR artifacts are sometimes overlooked. More specifically, there exists a wide range of other important ways of engendering trust, including the provision of profile photos, self-descriptions, and platform-issued labels.

In this chapter, we propose a conceptual framework for the diverse landscape of UR artifacts and link their cause-and-effect relationships to theory (Sect. 2). We then survey empirical findings on the pathways captured in the framework (Sect. 3), present data from a case study on Airbnb hosts and guests (Sect. 4), discuss ongoing discourse and developments (Sect. 5), and provide concluding thoughts (Sect. 6).

\section{Theoretical Background}

\subsection{Signaling and Social Presence Theory}

The way UR artifacts engender trust can roughly be described by two, partially overlapping routes. First, UR artifacts can serve to signal a user's trustworthiness (Spence 1973). This acknowledges that, like many other markets, transactions on sharing platforms feature information asymmetry between providers and consumers. Through the signal, a user demonstrates a track record of trustworthy behavior. In most cases, it is the provider who sends the signal. In some cases, however, consumers also have to market themselves and demonstrate their trust- 
worthiness in order to be given permission to book (Karlsson et al. 2017). Since self-references cannot work through this route ("talk is cheap"), the involvement of a third party is required. This is reflected in the omnipresence of numerical and textual rating and review systems. In most cases, platforms use mutual rating systems, through which providers and consumers evaluate each other once a transaction has been completed. Thereby, they build up a reputation over time, reflecting the cumulative and aggregated experiences of prior transaction partners, which serves as a leap of faith for future ones. Moreover, ratings are usually provided simultaneously, avoiding (or at least mitigating) the detrimental effects of collusion and fear of retaliation.

The second route is described by social presence theory (Cyr et al. 2009; Gefen and Straub 2003; Short et al. 1976). Since the entire pre-purchase phase is carried out online (platform-, online-, and screen-mediated), the evolutionary processes and channels through which people conventionally establish trust are not available (e.g., physical closeness, body language, subtle gestures and countenance, biological messengers). At the same time, however, trust is even more essential in this setup due to information asymmetry and low (perceived) accountability and accessibility in case of problems. To bridge this trust gap, platform operators attempt to convey social cues through the platform's web interface. The resulting social presence can be understood as "the degree of salience of the other person in the interaction and the consequent salience of the interpersonal relationships" (Short et al. 1976, p. 65), as enabled by the communication medium. As any pre-transactional communication is mediated through the platform, perceived social presence reflects how different UR artifacts convey a sense of the other person being psychologically present. It is through this social presence that UR artifacts engender trust—even without "proof." Prime examples of cues to achieve this are profile photos, self-descriptions, and the provision of other personal data.

\subsection{Framework of User Representation Artifacts}

As outlined above, many (sharing) platform operators make use of a variety of mechanisms, systems, and UR artifacts that enable the display of personal as well as transactional information. Importantly, trust is a multidimensional construct and involves different actors and relations on sharing platforms (Hawlitschek et al. 2016d). It is hence important to differentiate between the main actors involved. With regard to the "source" of UR artifacts, it can be distinguished between the users themselves (who, e.g., upload a photo or write a self-description), other users (who, e.g., write text reviews or issue star ratings), and the platform (which, e.g., collects, aggregates, and displays corroboratory or transactional information about users, infers data (Custers 2018), awards badges, and verifies identities).

Additionally, artifacts can be distinguished by the type of information they convey (e.g., personal/non-personal) and their visual display (e.g., pictorial, numerical, textual). Last, there are the resulting user perceptions, behaviors, and market out- 


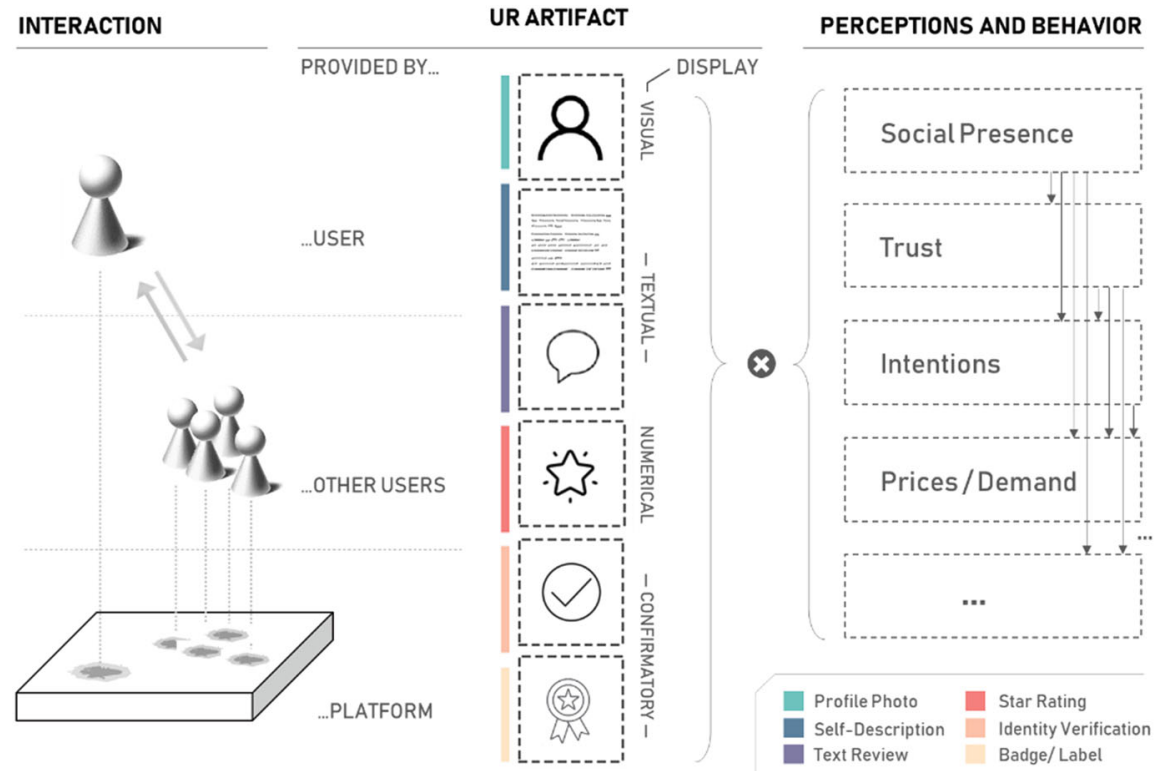

Fig. 1 Sharing economy UR artifact framework

comes caused by the artifacts' presence and specific properties (e.g., social presence, trust, purchase intentions, prices, demand, etc.), which are usually interdependent. Figure 1 summarizes this platform-user interaction, UR artifacts, and outcome variables.

\section{User Representation Artifacts}

In the following, we explore some of the empirical evidence among the UR artifacts as provided in Fig. 1. There is ample research on the use and effects of UR artifacts in the sharing economy — especially on Airbnb (Dann et al. 2019)—which serves both as a prime example and a testbed for platform-related research. Thereby, it is important to note that the UR artifacts employed by Airbnb are widely used across many other platforms.

Profile Photos Faces create trust (Teubner and Hawlitschek 2018). This basic human principle has been widely leveraged by the designers of social media and two-sided market platforms. Several ride-sharing platforms, for instance, prompted their users to complete their profiles, upload pictures, and even provide a filter to search for rides by drivers with a profile photo only. The beneficial effects of profile photos have been demonstrated for various contexts and applications, including accommodation sharing (Abramova 2020; Ert et al. 2016; Ert and Fleischer 2017; 
Jaeger et al. 2019), gift-giving networks (Teubner et al. 2013), trust experiments (Bente et al. 2012, 2014), corporate ideation processes (Wagenknecht et al. 2018), and equity crowdfunding (Klement and Teubner 2019). Importantly, avatars also engender social presence and trust in a similar way to actual photographs (Al Jaroodi et al. 2019; Teubner et al. 2013, 2014).

Self-Descriptions By deciding which information they disclose, users can determine how they are perceived by others (Tussyadiah and Park 2018). Selfdescriptions hence help to create a vivid picture of a particular person and hence allow them to be perceived as a real and multifaceted human being. By making use of self-descriptions, users can trigger expectations of economic and social value (Dann et al. 2020); induce feelings of connectedness, sociability, and intimacy; and hence increase liking and understanding (Altman and Taylor 1973; Janssen et al. 2014). While there exists a range of information that people frequently disclose, information on occupation, personal background, and personal interests is considered particularly beneficial (Ma et al. 2017; Tussyadiah 2016; Zhang et al. 2018).

Rating Scores The trust-building capacity of star ratings as well as the financial premium of a good reputation has been demonstrated repeatedly and for various contexts (Abramova et al. 2017; Teubner et al. 2017). Consequently, recent research has started to shift on the pitfalls and issues of rating systems, such as rating skewness (Teubner and Glaser 2018), rating inflation over time (Filippas et al. 2017), fake reviews (Moon et al. 2020; Wu et al. 2020), as well as rating response mechanisms and strategies (Abramova et al. 2015; Greiner et al. 2020).

Text Reviews The effects of text reviews on user trust and behavior are more complex than numerical scores as they differ in various dimensions such as length, language, valence, and context. Importantly, text reviews combine two important aspects of other trust cues as they are issued by third parties (i.e., credibility such as star ratings) and pertain to personal information (i.e., sociability such as selfdescriptions) (Dann et al. 2020). In contrast to most other UR artifacts, text reviews have received little research attention when it comes to assessing their effect through rigorous experimentation.

Identity Verification One means to counter uncertainty, especially against malicious actors on platforms, is identity verification. To do so, the user's face can be screened during a short webcam session, showing their ID card next to their face, possibly having a brief chat with a platform employee passing a basic sanity check. To indicate profile veracity, the platform then shows a small icon that signifies that the user's identity has been certified. While the general idea of verification is widespread across the sharing economy (Hawlitschek et al. 2016c; Mazzella et al. 2016), empirical evidence is still rather scarce. Verification was found to positively influence transaction intentions by increasing trust in the prospective transaction partners (Siegfried et al. 2020). In contrast to other true cues, verified IDs do not, however, necessarily reflect in price markups (Teubner et al. 2017; Xie and Mao 
2017). Yet, identity verification represents a popular tool for platform operators as it is inexpensive and can establish a very basic level of trust.

Badges Badges can be regarded as a means for platform operators to address existing weaknesses of reputation systems by introducing additional signals of stellar quality, allowing complementors to stand out even when five-star rating scores are omnipresent. In this regard, Airbnb's Superhost badge is one of the most prominent examples for such platform-generated cues (Liang et al. 2017). However, the origin of badges in the gamification literature suggests that their influence exceeds their add-on role in reputation systems. In fact, badges as a simple element of game design have the potential to increase user activity on (sharing) platforms in terms of transactions and comments (Hamari 2017).

Beyond such artifacts, there exist other relevant levers that platform operators employ to promote trust building, including the design (and size) of text input areas (Gebbia 2016) and even the choice of colors (Hawlitschek et al. 2016a). Note that truthful platform design and marketing claims are of particular importance to avoid perceptions of "sharewashing," which may backfire and undermine the platform's trustworthiness in the eyes of current and future consumers (Hawlitschek et al. 2018b). Moreover, beyond strategies to create and increase trust, some measures aim at lowering the necessary levels of trust for users to engage (i.e., the trust thresholds), for instance by providing insurance (Chica et al. 2019).

\section{Case Study: User Representation on Airbnb}

In this section, we report results from a data-based case study on how hosts and guests present themselves on the accommodation-sharing platform Airbnb through various UR artifacts. To do so, we draw on the online repository InsideAirbnb.com on listing data and user reviews and, based on this, run proprietary web crawlers to extract the relevant information from Airbnb.

Using InsideAirbnb's listing data (listings.csv), we identified a random sample of 5000 hosts based in Berlin, Germany, yielding information on name, profile image (URL), rating score, self-description, verifications, etc. Moreover, based on all reviews received by hosts in Berlin (reviews.csv) in 2019 (i.e., before the global emergence of COVID-19), we extracted a random sample of 5000 guests. Note that not every transaction is actually reflected in a review and estimates on this fraction vary. Hence this data will be somewhat biased toward "review-writing" guests. While, to the best of our knowledge, data on guests is not provided by any data repository, guests also have profile pages similar to hosts (i.e., a user ID) linked to a unique online profile. By analyzing these profiles, we investigated how guests represent themselves, including their profile image and self-description. For all $2 \times 5000=10,000$ user profiles (hosts and guests), we manually inspected and categorized the profile photos (portrait-like, multiple persons, etc.). This data allowed us to compare how hosts and guests differ in terms of presenting themselves 
Table 1 Summary statistics of hosts and guests

\begin{tabular}{l|l|l|l}
\hline UR artifact & Hosts & Guests & Dif. sig. $^{{ }^{2}}$ \\
\hline Has profile image & $99.4 \%$ & $97.0 \%$ & Yes \\
\hline Portrait-like photo & $72.6 \%$ & $73.3 \%$ & No \\
\hline Multiple persons & $11.4 \%$ & $15.0 \%$ & Yes \\
\hline Person/s visible but no face/s identifiable & $8.2 \%$ & $5.8 \%$ & Yes \\
\hline Objects, landscapes, or buildings & $6.2 \%$ & $2.1 \%$ & Yes \\
\hline$\quad$ Avatar & $1.0 \%$ & $0.8 \%$ & No \\
\hline Has self-description & $47.0 \%$ & $47.2 \%$ & No \\
\hline Explicit statement of occupation & $24.3 \%$ & $19.4 \%$ & Yes \\
\hline Has identity verification & $36.0 \%$ & $73.2 \%$ & Yes \\
\hline Average number of ratings/reviews & 19.7 & 10.7 & Yes \\
\hline Average rating score & 94.9 & - & - \\
\hline Also active on the opposite market side & $66.7 \%$ & $8.0 \%$ & Yes \\
\hline Has superhost badge ${ }^{\text {b }}$ & $14.4 \%$ & - & - \\
\hline Fraction of females ${ }^{(\text {based on name) }}$ & $52.4 \%$ & $49.2 \%$ & Yes \\
\hline
\end{tabular}

Note: a Significance of difference based on two-sample proportion test $(p<.05)$

${ }^{\mathrm{b}}$ Airbnb issues its superhost badge to "experienced hosts who provide a shining example for other hosts, and extraordinary experiences for their guests" based on transaction volume ( $\geq 10$ stays), rating score ( $\geq 4.8$ stars), response rate $(\geq 90 \%)$, and cancellation rate $(\leq 1 \%)$ (Airbnb 2020)

to the respective other market side. Table 1 provides summary statistics for the usage of UR artifacts by hosts and guests in the sample.

It is worth noting that hosts and guests are very similar in terms of how they present themselves on the platform. Specifically, both groups provide a profile photo almost all of the time, with very similar distributions on what these photos actually show. Moreover, both groups provide a self-description (47\%) as well as an explicit statement of their occupation with very similar frequency.

The only stark difference occurs with regard to identity verification, where only $36 \%$ of all hosts but $73.2 \%$ of all guests make use of this feature. Similarly, both market sides exhibit similar shares of male/female users. Overall, one could expect that this high similarity is rooted in a degree of "side-switching" on the platform (Stummer et al. 2018), that is, users who are active both as hosts and guests. However, while $66.7 \%$ of hosts also use the platform to travel themselves, only $8 \%$ of all guests are also active as hosts. One possible explanation for this symmetry is the fact that the trust requirements are also mutual due to the high degree of economic and social exposure both for hosts and guests. In consequence, there appears to have emerged a common platform etiquette agreed upon by both market sides. 


\section{Discussion}

We shape our tools, and thereafter our tools shape us. (John Culkin)

In the sense of Culkin's bon mot, the selection, design, and use of UR tools have tremendous importance for how our (social and economic) online lives are organized (i.e., who gets what). Such tools must hence not be underestimated. Specifically, as UR artifacts depict actual people, they are likely to reproduce many of the problems inherent to social interactions (e.g., discrimination). Take the most common reputation systems as an example. While objectively designed to be equal for everyone, people's online reputation will, not least, depend on whether they manage to conduct their first transactions successfully. However, based on stereotypes and other factors, not everyone is "equally likely to obtain a first review" at all (Kas 2020, p. 13). Reputation systems may hence even exacerbate gender-, age-, or ethnicity-based inequality. This holds particularly true for sharing platforms, considering that platforms and platform paradigms play an ever-increasing role in our professional and private lives-and their strong dependence on personal characteristics. This also concerns a broad variety of domains, be it for booking accommodation (e.g., Airbnb, Booking.com), finding real estate (e.g., ImmoScout24), ride sharing (e.g., BlaBlaCar, Zimride), selling and buying used goods (e.g., eBay, Gumtree), crowdwork platforms for cleaning (e.g., Helpling), or other tasks (e.g., TaskRabbit, MyHammer), to name just a few.

Given this variety of contexts and perspectives, as we have demonstrated in the previous sections, UR needs to be understood in view of factors such as platform commerciality (e.g., Airbnb vs. Couchsurfing), user professionalism (e.g., eBay vs. Etsy), and user role (e.g., provider vs. consumer). Moreover, requirements will be different for different resource types (i.e., products/services; Hawlitschek et al. 2018c) and the implied degree of social interaction (Hesse et al. 2020a). Last, how and by whom matches are made (e.g., by the users or by the platform) is decisive (Hawlitschek et al. 2016b). Hence, different platforms will leverage different trust cues and combinations thereof to their users but, ultimately, to their own benefit. Much of the information systems literature tends to understand UR as a means to an end, for example, for trust building. In this sense, the main stance is often positive. Yet, despite the undisputed beneficial effects of UR, conveying personal information via these artifacts is not necessarily a straightforward decision, and there are a range of caveats that need to be taken into account. We will briefly touch on four views on the use of UR that have typically either received less attention or are still in emerging states.

1. Privacy and Discrimination-Users, platform operators, and regulators have to balance competing interests such as trust building versus protecting user privacy (Teubner and Flath 2019) and mitigating discrimination (Airbnb 2016; Cui et al. 2020; Edelman et al. 2017). Especially profile photos and user names are likely to lead to ethnicity-based discrimination. One response to this (as indicated by the case study above) seems to be that hosts, who are typically much more 

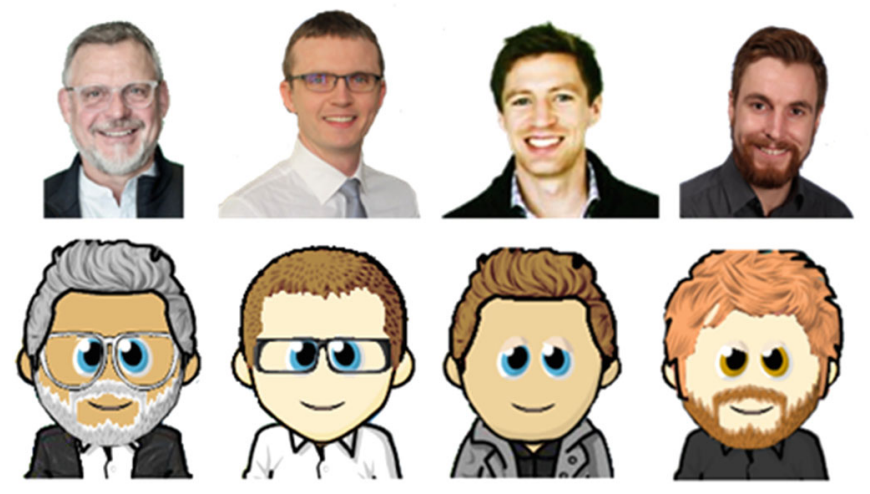

Fig. 2 Avatar examples

accessible to the general public than guests, use semi- or fully anonymous photos. In fact, hosts employ objects, buildings, and landscapes three times more often and obscured faces $40 \%$ more often than guests (see Table 1). Another avenue to address the issue of discrimination may be found in the way the different artifacts and other trust cues interact. For instance, while Edelman et al. (2017) found evidence of discrimination against users with distinctively African American (vs. distinctively white) names, Cui et al. (2020) found that this effect disappears once online reputation is available.

It is hence not surprising that some users have reservations about providing personal data online but_at the same time - the need for building trust (in other people, organizations, and digital services) is only increasing. One means to address this dilemma could be trusted agencies that provide certified UR without publishing the underlying data. Similar to the identity verification process described above, profile photos could be verified and replaced by avatars that credibly portray some of the actual facial features (see Fig. 2). Such images are capable of conveying trust levels comparable to the actual photos (Teubner et al. 2013, 2014), without giving away one's actual photo (and the associated biometric information).

2. Cross-platform Use-As of today, platforms operate in mostly unconnected silos where each platform maintains its own set of UR artifacts and typically its own reputation system. Given the personal and social importance of UR for trust building and the fact that people use an increasing number of platforms, it should be asked how trust building may also be achieved across platform boundaries. Profiles may, for instance, refer back to information centrally stored elsewhere, for example, to social media accounts or digital identity aggregation services. Recent research has explored the notion of cross-platform signaling based on numerical rating scores (Hesse et al. 2020b; Hesse and Teubner 2019, 2020; Otto et al. 2018; Teubner et al. 2019, 2020). In fact, several e-commerce platforms already offer functions that allow ratings to be imported from other platforms 
(e.g., Bonanza.com and Truegether.com, allowing rating imports from eBay and Amazon).

3. Fake Reviews-As outlined above, a particularly potent form of UR is ratings and reviews. Unsurprisingly, there has emerged a secondary (and largely illegal) market for this form of reputation. Meanwhile, there is also a rich body of literature on the prevalence and detection of fake reviews for e-commerce platforms (e.g., Amazon), travel platforms (e.g., Yelp, Tripadvisor, Booking.com), app stores, and many more (Wu et al. 2020). Such platforms are particularly prone to fake reviews as they mostly represent open environments in which almost anyone can rate a product, app, hotel, restaurant, employer, medical doctor, or accommodation at little to no cost. However, hardly any research has considered the role of fake reviews within the more secluded environments of sharing economy platforms (such as Airbnb or BlaBlaCar) where the privilege to submit a rating is directly linked to having actually concluded a transaction (including payment). This is by no means to say that there are no fake reviews in such environments, only that the hurdles to (a) commissioning and (b) detecting such reviews are higher. In fact, companies that offer reviews (e.g., fivestarmarketing.net) list a wide range of target markets including Amazon, app stores, Google, Facebook, Tripadvisor, and Jameda, but none of the popular sharing economy platforms (Ge and Voß 2020). Future work may hence want to take a closer look at the prevalence, causes, and effects of fake reviews on sharing economy platforms.

4. Other Forms of UR-In times of increasing numbers of online video conferences, it is highly conceivable that video formats will also find their way into the sharing economy. It is noteworthy that placement services such as Talentcube use videos to let job seekers present themselves to employers. Depending on context, other forms such as comp cards, git repositories, StackOverflow accounts, or even physiological data may be used (Peukert et al. 2018). Furthermore, it will be interesting to see how developments in IT and platform infrastructure affect user representation. While the use of distributed ledger technology is repeatedly being proposed for sharing economy applications, it is doubtful whether any application that involves physical interactions lends itself well to this technology (Hawlitschek et al. 2018a, 2020).

\section{Concluding Note}

You never get a second chance to make a first impression. (Andrew Grant)

Given that almost all sharing economy transactions are facilitated between strangers, UR artifacts replace face-to-face encounters in conveying first impressions. In this chapter, we have proposed a conceptual framework that captures the provision and display of widely used UR artifacts and briefly depicted the rich body of empirical evidence on their impact on user perception and behavior. Our analysis 
shows that UR artifacts play a critical role in the formation of transactions in the sharing economy, and we observe a range of commonalties in how platforms employ them. We conclude that the role of UR artifacts on sharing economy platforms goes well beyond that of enriching the look and feel of the platform's user interface, even for artifacts that convey features which are not independently verified (e.g., profile photos, self-descriptions). Each individual element has important implications for the way users perceive the level of sociality on the platform, the degree to which they trust one another, and, ultimately, their willingness to engage in actual transactions. Further, our case study on Airbnb demonstrated the strong uptake of UR artifacts by both hosts and guests. We hope that this work provides a useful frame of reference for researchers and practitioners interested in facilitating trust and transactions in the sharing economy.

Acknowledgment This publication was supported by the Open Access fund of Technische Universität Berlin. Support is gratefully acknowledged.

\section{References}

Abramova, O. 2020. "Does a smile open all doors? Understanding the impact of appearance disclosure on accommodation sharing platforms," in HICSS 2020 Proceedings, pp. 831-840.

Abramova, O., Shavanova, T., Fuhrer, A., Krasnova, H., and Buxmann, P. 2015. "Understanding the sharing economy: The role of response to negative reviews in the peer-to-peer accommodation sharing network," in ECIS 2015 Proceedings, pp. 1-16.

Abramova, O., Krasnova, H., and Tan, C.-W. 2017. "How much will you pay? Understanding the value of information cues in the sharing economy," in ECIS 2017 Proceedings, pp. 1-18.

Airbnb. 2016. "Airbnb's nondiscrimination policy: Our commitment to inclusion and respect," (available at https://www.airbnb.com/help/article/1405/airbnb-s-nondiscriminationpolicy\%2D\%2Dour-commitment-to-inclusion-and-respect; retrieved September 14, 2017).

Airbnb. 2020. "How do I become a Superhost?," (available at https://www.airbnb.com/help/article/ 829/how-do-i-become-a-superhost; retrieved October 23, 2020).

Al Jaroodi, H., Chiong, R., Adam, M. T. P., and Teubner, T. 2019. "Avatars and embodied agents in information systems research: A systematic review and conceptual framework," Australasian Journal of Information Systems, (23), pp. 1-37.

Altman, I., and Taylor, D. A. 1973. Social Penetration: The Development of Interpersonal Relationships, Holt, Rinehart \& Winston.

Bente, G., Baptist, O., and Leuschner, H. 2012. "To buy or not to buy: Influence of seller photos and reputation on buyer trust and purchase behavior," International Journal of Human Computer Studies, (70:1), pp. 1-13.

Bente, G., Dratsch, T., Kaspar, K., Häßler, T., Bungard, O., and Al-Issa, A. 2014. "Cultures of trust: Effects of avatar faces and reputation scores on German and Arab players in an online trust-game," PLOS ONE, (9:6), pp. 1-7.

Chica, M., Chiong, R., Adam, M. T. P., and Teubner, T. 2019. "An evolutionary game model with punishment and protection to promote trust in the sharing economy," Nature Scientific Reports, (9), p. 19789.

Cui, R., Li, J., and Zhang, D. 2020. "Reducing discrimination with reviews in the sharing economy: Evidence from field experiments on Airbnb," Management Science, (66:3), pp. 1071-1094. 
Custers, B. 2018. "Profiling as inferred data. Amplifier effects and positive feedback loops," in Being Profiled: Cogitas Ergo Sum. 10 Years of "Profiling the European Citizen," E. Bayamlioğlu, I. Baraliuc, and L. Janssens (eds.), Amsterdam University Press.

Cyr, D., Head, M., Larios, H., and Pan, B. 2009. "Exploring human images in website design: A multi-method approach," MIS Quarterly, (33:3), pp. 539-566.

Dann, D., Teubner, T., and Weinhardt, C. 2019. "Poster child and guinea pig-Insights from a structured literature review on Airbnb," International Journal of Contemporary Hospitality Management, (31:1), pp. 427-473.

Dann, D., Teubner, T., Adam, M. T. P., and Weinhardt, C. 2020. "Where the host is part of the deal: Social and economic value in the platform economy," Electronic Commerce Research and Applications, (40), p. 100923.

Edelman, B. G., Luca, M., and Svirsky, D. 2017. "Racial discrimination in the sharing economy: Evidence from a field experiment," American Economic Journal: Applied Economics, (9:2), pp. 1-22.

Ert, E., and Fleischer, A. 2017. "What in a photo makes you trust a person online? A structural equation modeling approach," Working Paper, pp. 1-17.

Ert, E., Fleischer, A., and Magen, N. 2016. "Trust and reputation in the sharing economy: The role of personal photos in Airbnb," Tourism Management, (55:1), pp. 62-73.

Filippas, A., Horton, J. J., and Golden, J. 2017. "Reputation in the long-run," Working Paper.

Ge, L., and Voß, S. 2020. "Managing information in the case of opinion spamming," in Design, User Experience, and Usability: Interaction Design, A. Marcus and E. Rosenzweig (eds.), Springer, pp. 370-384.

Gebbia, J. 2016. "How Airbnb designs for trust," (available at https://bit.ly/2SOa4PH; retrieved December 12, 2019).

Gefen, D., and Straub, D. W. 2003. "Managing user trust in B2C e-services," e-Service Journal, (2:2), pp. 7-24.

Greiner, B., Teubner, T., and Weinhardt, C. 2020. "How to design trust on market platforms?," Schmalenbachs Zeitschrift für betriebswirtschaftliche Forschung, (in press).

Hamari, J. 2017. "Do badges increase user activity? A field experiment on the effects ofgamification," Computers in Human Behavior, (71), pp. 469-478.

Hawlitschek, F., Jansen, L. E., Lux, E., Teubner, T., and Weinhardt, C. 2016a. "Colors and trust: The influence of user interface design on trust and reciprocity," in HICSS 2016 Proceedings, pp. 590-599.

Hawlitschek, F., Teubner, T., Adam, M. T. P., Borchers, N., Möhlmann, M., and Weinhardt, C. 2016b. "Trust in the sharing economy: An experimental framework," in ICIS 2016 Proceedings, pp. 1-14.

Hawlitschek, F., Teubner, T., and Gimpel, H. 2016c. "Understanding the sharing economyDrivers and impediments for participation in peer-to-peer rental," in HICSS 2016 Proceedings, pp. 4782-4791.

Hawlitschek, F., Teubner, T., and Weinhardt, C. 2016d. "Trust in the sharing economy," Swiss Journal of Business Research and Practice, (70:1), pp. 26-44.

Hawlitschek, F., Notheisen, B., and Teubner, T. 2018a. "The limits of trust-free systems: A literature review on blockchain technology and trust in the sharing economy," Electronic Commerce Research and Applications, (29), pp. 50-63.

Hawlitschek, F., Stofberg, N. O., Teubner, T., Tu, P., and Weinhardt, C. 2018b. "How corporate sharewashing practices undermine consumer trust," Sustainability, (10:8), pp. 1-18.

Hawlitschek, F., Teubner, T., and Gimpel, H. 2018c. "Consumer motives for peer-to-peer sharing," Journal of Cleaner Production, (204), pp. 144-157.

Hawlitschek, F., Notheisen, B., and Teubner, T. 2020. "A 2020 perspective on The limits of trustfree systems: A literature review on blockchain technology and trust in the sharing economy," Electronic Commerce Research and Applications, (40), p. 100935.

Hesse, M., and Teubner, T. 2019. "Reputation portability - quo vadis?," Electronic Markets, (29:5), pp. 1083-1119. 
Hesse, M., and Teubner, T. 2020. "Takeaway trust: A market data perspective on reputation portability in electronic commerce," in HICSS 2020 Proceedings, pp. 5119-5128.

Hesse, M., Dann, D., Braesemann, F., and Teubner, T. 2020a. "Understanding the platform economy: Signals, trust, and social interaction,” in HICSS 2020 Proceedings, pp. 5139-5148.

Hesse, M., Teubner, T., and Adam, M. T. P. 2020b. "Bring your own stars-The economics of reputation portability," in ECIS 2020 Proceedings, pp. 1-11.

Jaeger, B., Sleegers, W. W. A., Evans, A. M., Stel, M., and van Beest, I. 2019. "The effects of facial attractiveness and trustworthiness in online peer-to-peer markets," Journal of Economic Psychology, (75:102125).

Janssen, J. H., IJsselsteijn, W. A., and Westerink, J. H. D. M. 2014. "How affective technologies can influence intimate interactions and improve social connectedness," International Journal of Human-Computer Studies, (72:1), pp. 33-43.

Karlsson, L., Kemperman, A., and Dolnicar, S. 2017. "May I sleep in your bed? Getting permission to book," Annals of Tourism Research, (62:1), pp. 1-12.

Kas, J. 2020. "Trust and reputation in the peer-to-peer platform economy," Dissertation, Utrecht University.

Klement, F., and Teubner, T. 2019. “Trust isn't blind: Exploring visual investor cues in equity crowdfunding," in ICIS 2019 Proceedings, pp. 1-9.

Liang, S., Schuckert, M., Law, R., and Chen, C.-C. 2017. "Be a 'Superhost': The importance of badge systems for peer-to-peer rental accommodations," Tourism Management, (60), pp. 454465.

Ma, X., Hancock, J. T., Mingjie, K. L., and Naaman, M. 2017. "Self-disclosure and perceived trustworthiness of Airbnb host profiles," in CSCW 2017 Proceedings, pp. 1-13.

Mazzella, F., Sundararajan, A., Butt d'Espous, V., and Möhlmann, M. 2016. "How digital trust powers the sharing economy: The digitization of trust," IESE Insight, (30:3), pp. 24-31.

Moon, S., Kim, M. Y., and Iacobucci, D. 2020. "Content analysis of fake consumer reviews by survey-based text categorization," International Journal of Research in Marketing, p. in press.

Otto, L., Angerer, P., and Zimmermann, S. 2018. "Incorporating external trust signals on service sharing platforms," in ECIS 2018 Proceedings, pp. 1-17.

Peukert, C., Adam, M. T. P., Hawlitschek, F., Helming, S., Lux, E., and Teubner, T. 2018. "Knowing me, knowing you: Biosignals and trust in the surveillance economy," in ICIS 2018 Proceedings, pp. 1-11.

Short, J., Williams, E., and Christie, B. 1976. The Social Psychology of Telecommunications, John Wiley \& Sons Ltd, London.

Siegfried, N., Löbbers, J., and Benlian, A. 2020. "The trust-building nature of identity verification in the sharing economy: An online experiment," in WI 2020 Proceedings, pp. 1-16.

Spence, M. 1973. "Job market signaling," Quarterly Journal of Economics, (87:3), pp. 355-374.

Stummer, C., Kundisch, D., and Decker, R. 2018. "Platform launch strategies," Business \& Information Systems Engineering, (60:2), pp. 167-173.

Teubner, T., and Flath, C. M. 2019. "Privacy in the sharing economy," Journal of the Association for Information Systems, (20:3), pp. 213-242.

Teubner, T., and Glaser, F. 2018. "Up or out-The dynamics of star rating scores on Airbnb," in ECIS 2018 Proceedings, pp. 1-13.

Teubner, T., and Hawlitschek, F. 2018. "The economics of peer-to-peer online sharing," in The Rise of the Sharing Economy: Exploring the Challenges and Opportunities of Collaborative Consumption, P. Albinsson and Y. Perera (eds.), Praeger Publishing, pp. 129-156.

Teubner, T., Hawlitschek, F., Adam, M. T. P., and Weinhardt, C. 2013. "Social identity and reciprocity in online gift giving networks," in HICSS 2013 Proceedings, pp. 708-717.

Teubner, T., Adam, M. T. P., Camacho, S., and Hassanein, K. 2014. "Understanding resource sharing in C2C platforms: The role of picture humanization," in ACIS 2014 Proceedings, pp. $1-10$.

Teubner, T., Hawlitschek, F., and Dann, D. 2017. "Price determinants on Airbnb: How reputation pays off in the sharing economy," Journal of Self-Governance and Management Economics, (5:4), pp. 53-80. 
Teubner, T., Hawlitschek, F., and Adam, M. T. P. 2019. "Reputation transfer," Business \& Information Systems Engineering, (61:2), pp. 229-235.

Teubner, T., Adam, M. T. P., Hawlitschek, F. 2020. "Unlocking online reputation: On the effectiveness of cross-platform signaling in the sharing economy," Business \& Information Systems Engineering, (62:6), pp. 501-513.

Tussyadiah, I. P. 2016. "Strategic self-presentation in the sharing economy: Implications for host branding," in Information and Communication Technologies in Tourism, pp. 695-708.

Tussyadiah, I. P., and Park, S. 2018. "When guests trust hosts for their words: Host description and trust in sharing economy," Tourism Management, (67), pp. 261-272.

Wagenknecht, T., Teubner, T., and Weinhardt, C. 2018. "A Janus-faced matter-The role of user anonymity for communication persuasiveness in online discussions," Information \& Management, (55), pp. 1024-1037.

Wu, Y., Ngai, E. W., Wu, P., and Wu, C. 2020. "Fake online reviews: Literature review, synthesis, and directions for future research," Decision Support Systems, (132), p. 113280.

Xie, K., and Mao, Z. 2017. "The impacts of quality and quantity attributes of Airbnb hosts on listing performance," International Journal of Contemporary Hospitality Management, (29:9), pp. 2240-2260.

Zhang, K. Z. K., Barnes, S. J., Zhao, S. J., and Zhang, H. 2018. "Can consumers be persuaded on brand microblogs? An empirical study," Information \& Management, (55:1), pp. 1-15.

Timm Teubner is an assistant professor of Trust in Digital Services at the Einstein Center Digital Future (ECDF) and TU Berlin. The main focuses of his work are digital platforms, including trust and reputation systems, human-computer interaction, and crowdsourcing. He approaches these subjects from a socio-technical perspective, including the investigation of user behavior and psychology, and technical, legal, as well as strategic aspects. In 2010, he received a diploma in Industrial Engineering and Management from the Karlsruhe Institute of Technology (KIT). In 2013, he received his doctoral degree in Information Systems from KIT, supervised by Christof Weinhardt. His research has been published in international outlets such as the Journal of the Association for Information Systems, Business \& Information Systems Engineering, Electronic Markets, Information \& Management, and the Journal of Cleaner Production.

Marc T. P. Adam is an associate professor of Computing and Information Technology at the University of Newcastle, Australia. In his research, he investigates the interplay of users' cognition and affect in human-computer interaction. In 2006, he received an undergraduate degree in Computer Science from the University of Applied Sciences Würzburg, Germany. In 2010, he received a $\mathrm{PhD}$ in Information Systems from the Karlsruhe Institute of Technology, Germany, supervised by Christof Weinhardt. He is a founding member of the Society for NeuroIS. His research has been published in top international outlets such as Business \& Information Systems Engineering, Computers in Human Behavior, IEEE Journal on Biomedical and Health Informatics, IEEE Transactions on Affective Computing, the Journal of the Association for Information Systems, the Journal of Management Information Systems, and the Journal of Retailing.

Florian Hawlitschek is an affiliated researcher to the Chair of Trust in Digital Services in the Faculty of Economics and Management at TU Berlin. He works as an innovation manager for sustainability and digitization at the FES Frankfurter Entsorgungs- und Service GmbH (a German waste management company). In his prior academic work at the Karlsruhe Institute of Technology (Germany), he was supervised by Christof Weinhardt. His research has been published in outlets such as Business \& Information Systems Engineering, Die Unternehmung: Swiss Journal of Business Research and Practice, Electronic Commerce Research and Applications, the Journal of Cleaner Production, and Sustainability. 
Open Access This chapter is licensed under the terms of the Creative Commons Attribution 4.0 International License (http://creativecommons.org/licenses/by/4.0/), which permits use, sharing, adaptation, distribution and reproduction in any medium or format, as long as you give appropriate credit to the original author(s) and the source, provide a link to the Creative Commons licence and indicate if changes were made.

The images or other third party material in this chapter are included in the chapter's Creative Commons licence, unless indicated otherwise in a credit line to the material. If material is not included in the chapter's Creative Commons licence and your intended use is not permitted by statutory regulation or exceeds the permitted use, you will need to obtain permission directly from the copyright holder. 